\title{
Use of Computational Fluid Dynamics for Absorption Packed Column Design
}

\author{
Yacine Haroun* and Ludovic Raynal \\ IFP Energies nouvelles, Rond-point de l'échangeur de Solaize, BP 3, 69360 Solaize - France \\ e-mail: yacine.haroun@ifpen.fr - ludovic.raynal@ifpen.fr \\ * Corresponding author
}

\begin{abstract}
Computational Fluid Dynamics (CFD) is today commonly used in a wide variety of process industries and disciplines for the development of innovative technologies. The present article aims to show how CFD can be used as an effective analysis and design tool for the development and design of packed gas/liquid absorption columns. It is first shown how CFD can be used for the characterisation of packings. The different hydrodynamic and mass transfer design parameters are investigated and adapted CFD methods are suggested. Secondly, column distribution internal development is discussed to show how CFD simulations should be performed to improve the design of gas and liquid distributors. An example of the development of new distribution technologies for floating installation of a reactive absorption column is also presented.
\end{abstract}

Résumé - Utilisation de la dynamique des fluides numérique pour le design des colonnes d'absorption à garnissages - La dynamique des fluides numérique (Computational Fluid Dynamics, CFD) est aujourd'hui couramment utilisée pour le développement de technologies innovantes dans de nombreux domaines et procédés industriels. Cet article a pour objectif de montrer comment la CFD peut être utilisée comme outil d'analyse et de dimensionnement pour le développement des colonnes d'absorption gaz-liquide à garnissages. En premier, il est présenté comment la CFD peut être utilisée pour caractériser les différents paramètres de dimensionnement d'un garnissage (hydrodynamique et transfert). Les méthodes CFD appropriées sont suggérées et discutées. En second, l'utilisation de la CFD pour le développement et l'optimisation des internes de distribution gaz-liquide est exposée. Un exemple de développement par CFD d'une nouvelle technologie de distribution pour une colonne d'absorption réactive sur une installation flottante offshore est présenté. 


\section{INTRODUCTION}

Gas/liquid absorption operation constitutes an important aspect in several industrial applications using packed columns such as distillation, reactive distillation, acid gas removal and solvent-based post-combustion $\mathrm{CO}_{2}$ capture.

Reactive absorption packed columns consist of packing elements (structured or random packing) contacted by cocurrent or counter-current gas-liquid flow. Liquid mostly trickles over the packing's wall as film flow, with the gas being a continuous phase flowing within the core of the packing elements. The absorption of gases in the liquid solution is often accompanied by chemical reactions. The distribution of the liquid and gas phases in packing is ensured by the use of gas-liquid tray distributors situated at the top of each packed bed and the bottom gas distributor at the bottom of the column (Billet, 1995; Kister, 1990; Olujic et al., 2004; Stemich and Spiegel, 2011).

To meet the requirements of size optimisation of the column (in terms of height and diameter) and pressure drop limitation, efficient and high-capacity packings and appropriate design of the gas and liquid distributor are needed (Billet, 1995). The selection of the column internals requires a deep understanding of the purpose of the reactive absorption application and precise knowledge of the characteristics of the gas and liquid solvent flows throughout the packed bed in terms of hydrodynamics (pressure drop, flooding), mass transfer (gas-side and liquid-side mass transfer coefficients) and indirectly, kinetics and thermodynamics (reaction regime, reaction acceleration factor). These parameters are used in process simulations to achieve optimum design. For example, in the particular case of post-combustion $\mathrm{CO}_{2}$ capture, Raynal et al. (2013) showed that the interfacial area is the key parameter for the absorber design. This leads to promoting structured packings for such a reactive absorption application that offer higher geometric area per unit volume, from at least $250 \mathrm{~m}^{2} / \mathrm{m}^{3}$ and preferentially more than $350 \mathrm{~m}^{2} / \mathrm{m}^{3}$, and a large void fraction (porosity), around $90 \%$, which induce high mass transfer efficiency and low pressure drop, respectively (Lassauce et al., 2014). For high-pressure acid gas treatment, $\mathrm{H}_{2} \mathrm{~S}$ removal efficiency will be more sensitive to gas-side mass transfer, since $\mathrm{H}_{2} \mathrm{~S}$ reacts instantaneously with amine-based solvent, and, due to high-pressure operation, the column design will consider diameter optimisation as more important than height and resulting pressure drop optimisation; the corresponding choice of packing would thus differ from ambient pressure $\mathrm{CO}_{2}$ post-combustion absorption.

Much work and many experimental tests have been conducted in order to measure the packing characteristics and to develop adapted models (liquid holdup, effective area, gas-side and liquid-side mass transfer, pressure drop) for commercial packings (Billet, 1995; Bravo et al., 1985;
Fair and Bravo, 1990) and design rules for distribution technologies (Kister, 1990). However, developing understanding is still needed, especially for the development of new reactive absorption packings and internals, which involves various physical and geometrical parameters that cannot be easily investigated experimentally and are still not well understood. Besides, the corresponding experimental work is quite time-consuming and parametric optimisation is almost impossible.

In this context, Computational Fluid Dynamics (CFD) is seen as a powerful tool in complement to experimental work to investigate performance characteristics and the development of original reactive absorption columns (Charpentier, 2009). In the last decade, CFD has been used more and more to calculate flow characteristics in packed beds (Petre et al., 2003; Raynal and Royon-Lebeaud, 2007; Mohamed Ali et al., 2003). Indeed, the use of numerical simulation can provide a significant gain in time and could limit the number of experiments. Another reason to use CFD is the possibility of accessing information on a local scale which is not measurable with experimental methods.

The present article aims to show how CFD is used for the development of reactive absorption packed columns. Different CFD approaches and simulations are presented, addressing hydrodynamic and mass transfer characterisation of packings as well as distributing tray evaluation and development.

In the following first section, the use of CFD for the characterisation of packing is presented. The second section focuses on the development of gas and liquid distribution internals by using CFD.

\section{STRUCTURED PACKING CHARACTERISATION BY USING CFD}

As discussed in Raynal et al. (2013), the choice of the most adequate packing is linked to its performances in terms of pressure drop and mass transfer efficiency. There is no best packing which would offer high capacity, homogeneous distribution and good mass transfer efficiency, since from one case to another the expectations and sensitivity of the process differ. The capacity of the packing, giving the maximum gas and liquid mass flow rates, is used to determine the diameter of the column. This characteristic is often given by the pressure drop, and more exactly it corresponds to the flooding limit over which operation is no longer possible. The mass transfer efficiency is used to determine the height of the column. This latter characteristic is much more difficult to determine since, for reactive absorption application studied in the framework of the two-film theory, the mass transfer flux is linked to five parameters (Danckwerts, 1970). Three of these parameters are directly linked to the packing 
contactor geometry and the gas/liquid operating conditions. These parameters are the following: the liquid-side mass transfer coefficient, $k_{L}(\mathrm{~m} / \mathrm{s})$, the gas-side mass transfer coefficient, $k_{G}(\mathrm{~m} / \mathrm{s})$, and the interfacial effective area, $a_{e}\left(\mathrm{~m}^{-1}\right)$. The two remaining parameters correspond to the thermodynamic and kinetic performances of the solvent given, respectively, by the Henry coefficient, $H_{e}\left(\mathrm{~Pa}^{\mathrm{m}} \mathrm{m}^{3} \cdot \mathrm{mol}^{-1}\right)$, and the acceleration factor coefficient, $E(-)$, both varying with pressure and temperature conditions and with solvent loading. All these parameters are linked in the following relationship giving the flux for the chemical component $j$ from the gas to the liquid:

$\Phi_{j}\left(\mathrm{~mol} / \mathrm{m}^{3} / \mathrm{s}\right)=\left(\frac{1}{1 / k_{G} a_{e}+H_{e} / E k_{L} a_{e}}\right) \times\left(P_{j}-H_{e} C_{j, b u l k}\right)$

where: $P_{j}(\mathrm{~Pa})$ : the partial pressure of the component $j$ in the gas phase $C_{j, \text { bulk }}\left(\mathrm{mol} / \mathrm{m}^{3}\right)$ : the concentration of the component $j$ in the liquid bulk.

The characterisation of packing contactors consists of determining and modeling all parameters dealing with hydrodynamics and mass transfer. In recent years, several works can be found in the literature which deal with the CFD investigation of hydrodynamic (pressure drop, liquid hold-up, wetting, liquid distribution) and mass transfer design parameters (liquid- and gas-side mass transfer, acceleration factor, effective area mass transfer). Petre et al. (2003) were among the first authors to use CFD in order to calculate dry pressure drop in structured packings. They proposed an original approach by considering the structured packing by a combination of four Representative Elementary three-dimensional Units (REU). The total pressure drop in the packed bed was determined by combining CFD simulation results obtained in the different REU domains. The choice of the REU was further discussed by Raynal et al. (2004), who proposed considering the flow domain between two consecutive plates for gas flow calculations, or preferentially the smallest periodic element. More recently, Said et al. (2011) show that the pressure drop per unit length for a small number of REU is the same as for the entire column, which simplifies its computational modeling. Nikou and Ehsani (2008) tested different turbulence models to study wet and dry pressure drop and investigated heat and mass transfer in structured packings. Fernandes et al. (2009) presented a pseudo two-phase CFD model for determination of the wet pressure drops in a Sulzer EX packing.

Szulczewska et al. (2000) used the Volume Of Fluid (VOF) method to perform 2D simulations of counter-current gas-liquid flow on the structured packing Mellapak 250Y, first, to determine the effect of flow rates on the interfacial effective area, and second, to specify the lowest phase flow rate at which the packing becomes fully wetted. The interfacial area was determined by assuming that the $2 \mathrm{D}$ picture of flow in any cross-section of the packing is identical. Raynal et al. (2004) performed 2D CFD simulations with the VOF method to determine the liquid film thickness on a wavy plate similar to the packing surface, and the results were used to derive the liquid hold-up. Raynal and Royon-Lebeaud (2007) used the same VOF method for gas-liquid flow simulations on a small scale and the results are further used on a large scale in three-dimensional calculations with a geometry corresponding to a complete packed column. Ataki and Bart (2006) investigated the wetting in the structured packing elements of Rombopack using the same VOF method and used simulation results to develop correlations for the effective area and liquid hold-up. They also described the effect of liquid properties on wetting. Shojaee et al. (2011) investigated wet pressure drop and the effective area in Gempak 2A structured packing also by using the VOF method. The authors compare the evaluated effective area with existing correlations. They found good agreement with Brunazzi et al. (1995) model. More recently, Haroun et al. (2014) applied a VOF numerical model to investigate wetting phenomena, the effective interfacial area and liquid hold-up within a set of actual Mellapak 250X REU. The values of liquid-solid contact angles were varied to mimic the geometrical imperfections of the plate surface. The results showed significant variations in the wetted area depending on the liquid-solid contact characteristics and liquid flow rate. The authors pointed out the fact that experimental studies on wetting in structured packing are still needed to verify the numerical results.

Few works can be found in the literature which deal with CFD modeling of mass transfer in structured packings. Haroun et al. (2010a, b, 2012) extended hydrodynamic studies by further implementing liquid-side mass transfer and reactive mass transfer calculations by considering a 2D approach assuming full wetting of the packing using the VOF approach. They show how the liquid flow rate and the complex geometry of packing affect the liquid film flow topology and interfacial mass transfer. The authors reported good agreement between CFD results and the Higbie penetration theory when the adequate exposure time is used. For reactive mass transfer, their results show a good match between the numerical predictions and the theoretical relationship between the Hatta number and the enhancement factor for both first- and second-order reactions. More recently, Sebastia-Saez et al. $(2013,2014)$ developed a three-dimensional VOF model on a small scale for hydrodynamics and implemented physical mass transfer as a source term using the Higbie approach. The authors performed CFD simulation to study transient behaviour and the impact of the liquid load on the absorption rate in structured packing.

Regarding gas-side mass transfer investigation using CFD, only a few studies can be found in the literature; 
indeed, most of the studies focused only on hydrodynamics or liquid-side mass transfer. Erasmus (2004) was one of the first to use CFD to simulate gas-side mass transfer in structured packing. The author performed CFD simulations of naphthalene sublimation in simplified sections of structured packing. He found that using a BSL turbulence model gives satisfactory agreement between CFD calculations and experimental measurements. He points out, however, the sensitivity of the results to the placement of inlet and outlet boundaries. He found that a distance equal to the corrugation base was found to be adequate. Recently, Lautenschleger et al. (2015) used CFD to analyse the impact of flow behaviour on gas-side mass transfer in new and conventional structured packings. The authors reported good agreement between numerical simulation and literature modeling for Sulzer BX and Montz B1-500 commercial structured packings.

It is known that liquid dispersion in packing is strongly linked with the packing geometry (Fourati et al., 2012). The quality of distribution inside the packing is crucial for the mass transfer and thus the efficiency of the reactive absorption column. The gas-liquid distribution behaviour inside packed beds was mostly given by industrial experience and little comes from more scientific explanations. Recently, the large-scale two-fluid CFD simulation approach has been developed and used more and more to study such aspects. Mahr and Mewes (2007) proposed a CFD model for simulation of the macroscopic gas-liquid two-phase flow field in a column with structured packing. The model is based on the elementary cell model extended to be used on anisotropic porous structures such as corrugated structured packings. The numerical models are tested against $\mathrm{X}$-ray radiographic measurements on a quasi-twodimensional segment of structured packing and good agreement is reported. More recently, Fourati et al. (2013) developed a porous media CFD model in the framework of Eulerian two-fluid flows taking into account liquid dispersion in the packed zone. The authors compared CFD prediction of liquid spreading in the Mellapak 250X commercial packing previously studied by means of gamma-ray tomography, good agreement being observed. Soulaine et al. (2014) developed CFD modeling for simulation of gas-liquid flow on bistructured porous media representing structured packing. The set of macroscale equations that makes up the model combines three continuity equations and three multiphase Darcy's laws and is directly based on the Darcy generalised model. The authors compared the CFD results with the tomography imaging of Fourati et al. (2012) and show qualitative good agreement of the liquid distribution behaviour.

From the literature review, it clearly appears that most of the CFD work focused on structured packings. Indeed, achieving a representative loading domain of a random packing bed remains a complex challenge. However, with the development of the Discrete Element Simulation (DEM) loading simulation for complex geometry (Bai et al., 2009), the perspective of CFD simulation with random packing will soon become accessible. In this article, we will focus only on the structured packing contactors.

In the following, typical CFD approaches and simulations performed to determine physical design parameters in terms of hydrodynamics and mass transfer for structured packing geometry are presented. The different CFD approaches used for each physical parameter are introduced and discussed.

\subsection{Pressure Drop}

In this section, the ability of CFD to predict dry pressure (gas flow only) drop in different types of commercial structured packings (Sulzer Mellapak type or equivalent, such as Flexipac from Koch-Glitsch or B1-series from Montz) are presented and the results compared with experimental data. The purpose of this section is to present an appropriate approach to simulate dry pressure drop and thus to validate the straightforward CFD method to simulate gas flow in structured packing. As discussed in Petre et al. (2003) and Said et al. (2011), the dry pressure drop is an important design parameter, since it gives insight into the trend of the wet pressure drop performance. It thus leads to a first evaluation of the capacity of the packing.

Structured packings are made of corrugated metal sheets arranged side by side with opposing channel orientation. Channels are oriented with an angle from horizontal, $\theta$, which varies from $45^{\circ}$ for the $Y$ type of Mellapak packing to $60^{\circ}$ for the $X$ type. Figure 1a shows the triangular-based channel geometry of packing.

Structured packings are inherently periodic. Therefore, Representative Periodic Elements (RPE) were mostly used for the simulations, to reduce the CPU computational time. Different types of representative elements for corrugated sheet structured packings can be found in the literature. Petre et al. (2003) suggested a criss-crossing channel element. Raynal and Royon-Lebeaud (2007) and Said et al. (2011) proposed a geometry with periodic conditions at all cut boundaries. In this work, the second type of REU was considered. Figures 1b, c show the REU of Mellapak 250Y (M250Y) and M250X packing, respectively. In Figure 1a, it can be seen that the metal sheet of structured packing is not smooth, but is perforated and composed of small-scale texture (embossed metal sheet). For computing resource reasons, the wall texture of real packing and the perforation are not represented in simulated geometry. Indeed, in this work, the packing wall considered is smooth. A similar approach was considered by Raynal et al. (2004), and Nikou and Ehsani (2008) for the simulation of pressure drop in 


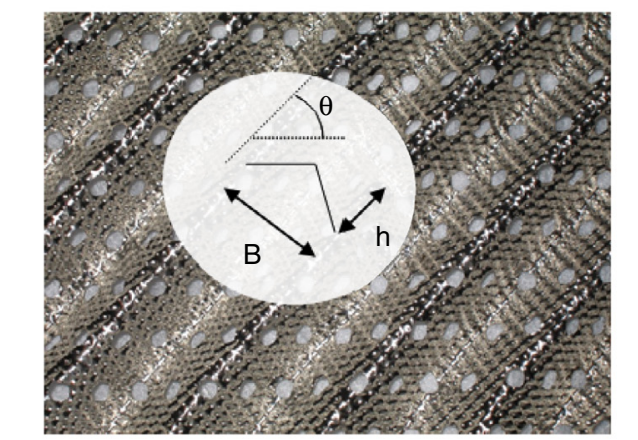

a)

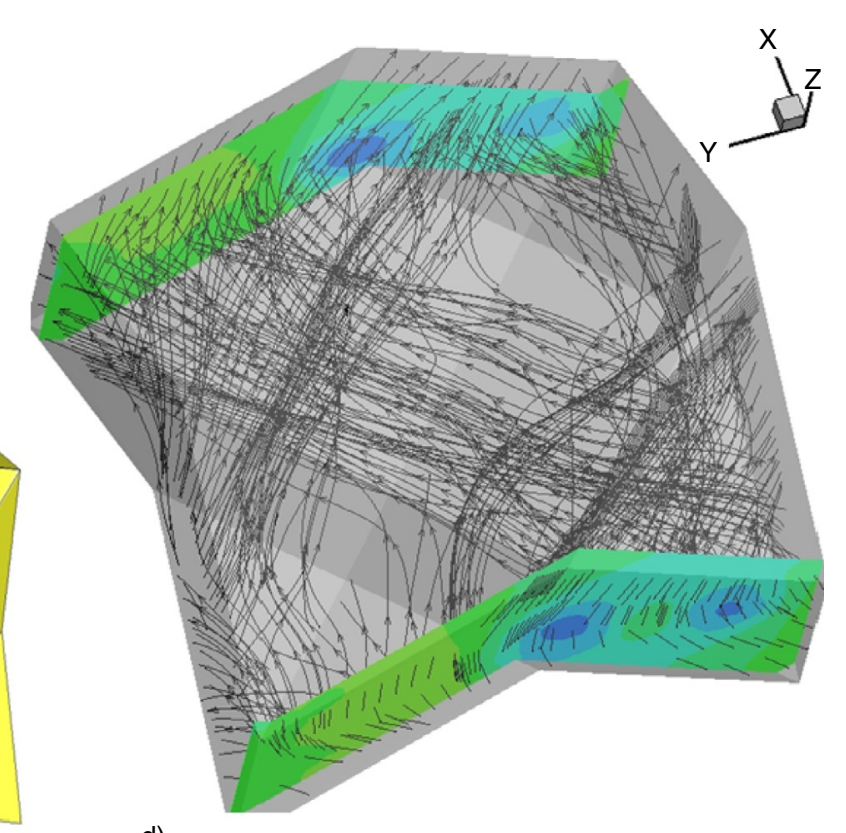

b)
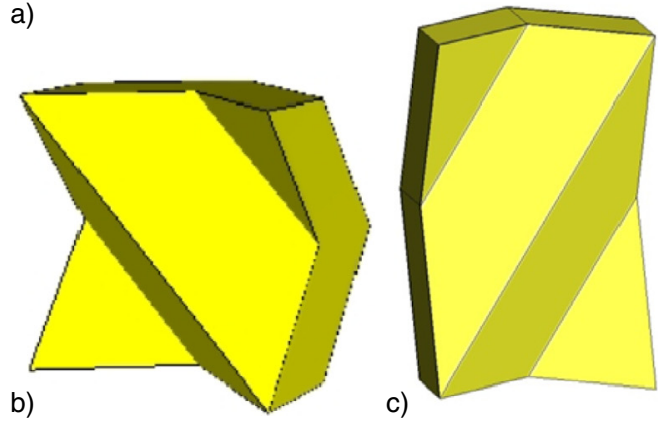

d)

Figure 1

a) Corrugation and surface geometries; b, c) illustration of the geometries considered for simulation, b) the periodic REU of M250Y, c) the REU of M250X, d) illustration of gas flow streamline in the REU of M250Y.

structured packings. As boundary conditions, opposite faces are considered periodic and a pressure gradient is imposed in the flow direction. The CFD simulations presented in this section were carried out with the commercial CFD software ANSYS Fluent 14.

One critical aspect of CFD simulations of gas flow for pressure drop in structured packings is choosing the appropriate turbulent model, especially when the range of gas Reynolds numbers is within laminar and fully turbulent flow, as discussed in Raynal et al. (2004). In order to determine the best CFD approach to simulate aerodynamics in structured packings, the results of two CFD turbulent models are presented in this work: Large-Eddy Simulation (LES) modeling and Reynolds Average Navier-Stokes models $k-\omega$ SST.

LES explicitly solves the large turbulent scales and modeling assumptions are restricted to small scales only. The subgrid model used is based on the Wall-Adapting Local Eddy-viscosity (WALE) model formulation of Nicoud and Ducros (1999). The assumptions of this model remain the same as in Smagorinsky's model but involve a local rotation rate in the expression of the turbulent viscosity; this is justified since dissipative scales are also characterised by a high rotation rate. The WALE model thus allows the prediction of the correct wall behaviour with an implicit damping effect.
The Shear Stress Transport (SST) $k$ - $\omega$ low Reynolds is based on model transport equations for turbulence kinetic energy $(k)$ and the specific dissipation rate $(\omega)$. This model blends the robust and accurate formulation of the $k$ - $\omega$ model in the near-wall region with the free-stream independence of the $k-\varepsilon$ model in the far field. For more details about this turbulent modeling, the reader is referred to the ANSYS user's guide.

In the simulations presented here, we paid attention to the validation of the mesh resolution. For near-wall treatment, the adapted mesh grid resolution near the wall region was adopted for each turbulent model; for example, for the $k-\omega$ models, to take full advantage of this formulation, the viscous sublayer is meshed with the $y+<1$. The mesh size used is such that the REU domain contains 600000 cells.

Figure 1d shows an example of simulation results with Mellapak 250Y structured packing (M250Y in the following). It shows gas flow streamlines in the REU considered. The picture shows the flow pattern in the packing channels. The streamline shapes confirm the preferential flow direction of the gas in the packed bed; indeed, the gas flow is oriented through the channel inclination angle. However, at the interaction face with the opposite channel orientation, part of the flow deviates the direction because of flow collisions. 


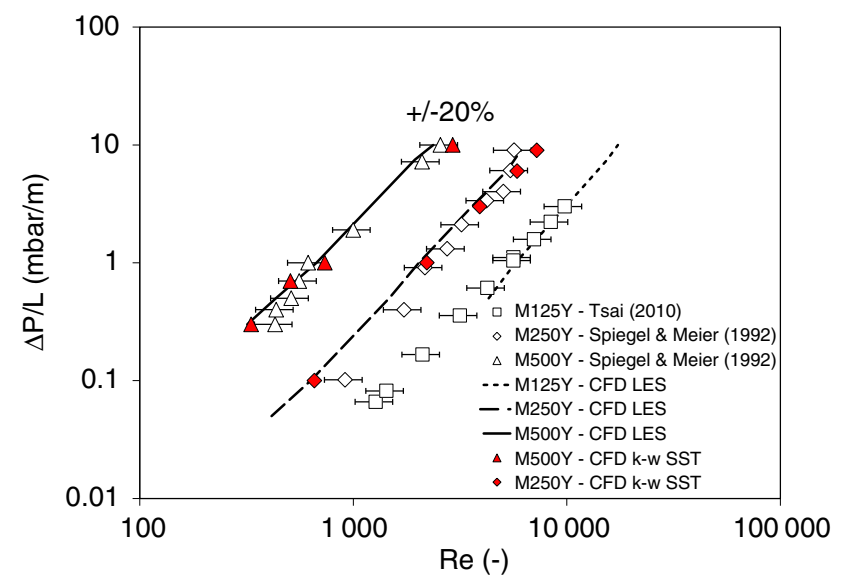

Figure 2

Experimental and simulated dry pressure drops versus Re number for the Mellapak 250Y REU.

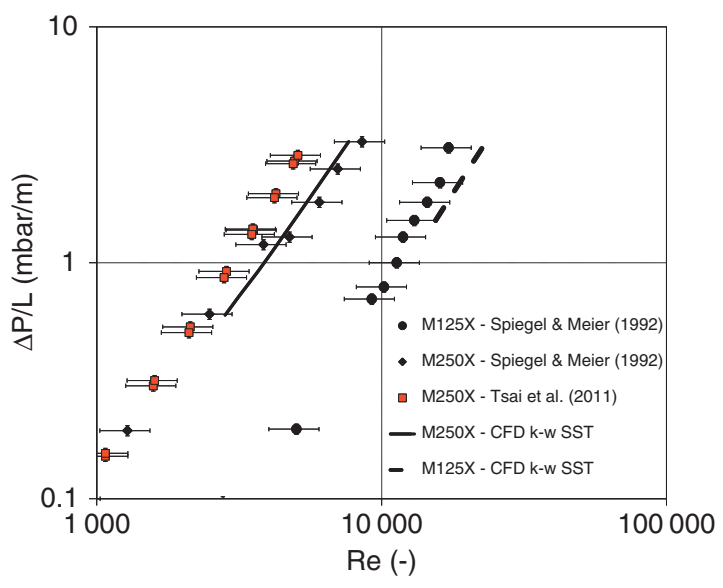

Figure 3

Experimental and simulated dry pressure drops versus Re number for the Mellapak 250X REU.
Figure 2 shows the predicted dry pressure drop versus Reynolds number for Mellapak 125Y, 250Y and 500Y, simulated using $k-\omega$ SST and LES turbulent models compared with the experimental results obtained by Spiegel and Meier (1992), the Reynolds number being calculated as follows:

$$
R e=\frac{\rho v_{S G} d_{e q}}{\mu} \text { with } d_{e q}=4 / a_{G}
$$

where $\rho\left(\mathrm{kg} / \mathrm{m}^{3}\right)$ is the gas density, $\mu$ (Pa.s) the gas dynamic viscosity, $a_{G}\left(\mathrm{~m}^{2} / \mathrm{m}^{3}\right)$ the geometric area of the packing and $v_{S G}(\mathrm{~m} / \mathrm{s})$ the superficial velocity.

The results show that the LES and $k$ - $\omega$ SST approaches are well adapted to determine dry pressure drop in structured packings. Indeed, the relative deviation between these two approaches and experimental data is less than $20 \%$. These results highlight that both LES and $k-\omega$ SST modeling is satisfactory, even if $k-\omega$ SST model results seem less precise at high Reynolds numbers than LES. However, taking into account the CPU resources necessary to run simulations using the LES model, using $k-\omega$ SST appears to be a very good compromise between simulation time and result accuracy. In Figure 3, only the $k-\omega$ SST low Reynolds model is used to determine pressure drop in M125X and M250X. The results are compared with the experimental data of Spiegel and Meier (1992) and Tsai et al. (2011). The simulated pressure drop in the REU is found to be in good agreement with the experimental results of Spiegel and Meier (1992). However, less good agreement is observed with the results of Tsai et al. (2011). This highlights the difficulty of the comparison exercise related to the fact that there are discrepancies in the literature data. However, good agreement is obtained with the experimental data of Spiegel and
Meier (1992) for the Mellapak $Y$ packing type as well as for the $X$ packing type.

To sum up, these studies showed that the basic gas flow behaviour and the dry pressure drop of the packing can be predicted fairly well by only one REU with the $k-\omega$ SST low Reynolds model. Furthermore, this work shows that CFD based on the REU element can be used as a fast and straightforward means for the investigation and optimisation of new packing geometries or benchmark pressure drop performance of different existing packing technologies.

\subsection{Physical and Reactive Liquid-Side Mass Transfer}

In recent years, with the development of numerical methods for simulating a deformable interface, the direct numerical investigation of interfacial reactive mass transfer in complex geometry has become possible. Haroun et al. (2010a, b) developed VOF modeling for physical and reactive mass transfer study in two-dimensional geometries corresponding to a slice of a structured packing. The computational method is based on the VOF method (Hirt and Nichols, 1981; Scardovelli and Zaleski, 1999), where the chemical species concentration equation is solved coupled with the NavierStokes equations by using the JADIM code developed at IMFT (Haroun et al., 2010a, b). The resolved equations are:

$$
\begin{gathered}
\nabla \cdot U=0 \\
\frac{\partial U}{\partial t}+U \cdot \nabla U=-\frac{1}{\rho} \nabla P+g+\frac{1}{\rho} \nabla \cdot T-F
\end{gathered}
$$




$$
\frac{\partial \alpha}{\partial t}+(V \cdot \nabla) \alpha=0
$$

$$
\begin{aligned}
& \frac{\partial C_{j}}{\partial t}+\nabla \cdot\left(U C_{j}\right)= \\
& \quad \nabla \cdot\left(D_{j} \nabla C_{j}-\left(D_{j} \frac{C_{j}\left(1-H e_{j}\right)}{\alpha+H e_{j}(1-\alpha)} \nabla \alpha\right)\right)+W_{j}
\end{aligned}
$$

where $U, P, \rho, g, T, F$ and $\alpha$ are the local velocity, pressure, density, dynamic viscosity, gravity, viscous deformation tensor, capillary force and volume fraction, respectively. The location of each phase is given by a scalar $\alpha$ (corresponding in most cases to the volume fraction). $C j$ is the chemical species concentration. $D_{j}$ is the molecular diffusivity, and $W_{j}$ is the production term related to the chemical reaction. For the calculation of capillary force, a continuum method (CSF) is employed, as proposed by Brackbill et al. (1992). An option to specify a wall adhesion angle in conjunction with the surface tension model is available in the VOF method.
A contact angle, $\gamma$, can be imposed at the wall. This latter is used to adjust the surface normal in cells near the wall (Haroun et al., 2014).

This approach takes into account the solubility of chemical species at the interface (Eq. 5) described by Henry's law (Haroun et al., 2010a, b). This formulation allows interpreting the jump of concentration at the interface as a continuous phenomenon, the Henry solubility law being converted into a solubility flux. This original modeling allows, from the gradient of concentration and flux of solubility, the determination of the local liquid mass transfer coefficient simultaneously with the evolution of the gas-liquid interface. This approach differs from recent studies of Sebastia-Saez et al. (2013, 2014) where the physical mass transfer is implemented in the VOF approach via a source term using Higbie modeling.

In Figure 4, the CFD results of Haroun et al. (2010a, b) on physical and reactive mass transfer obtained with the VOF approach are presented. For physical mass transfer, Haroun et al. (2010a, b, 2012) show that despite the complex geometry of structured packing, the CFD liquid-side mass
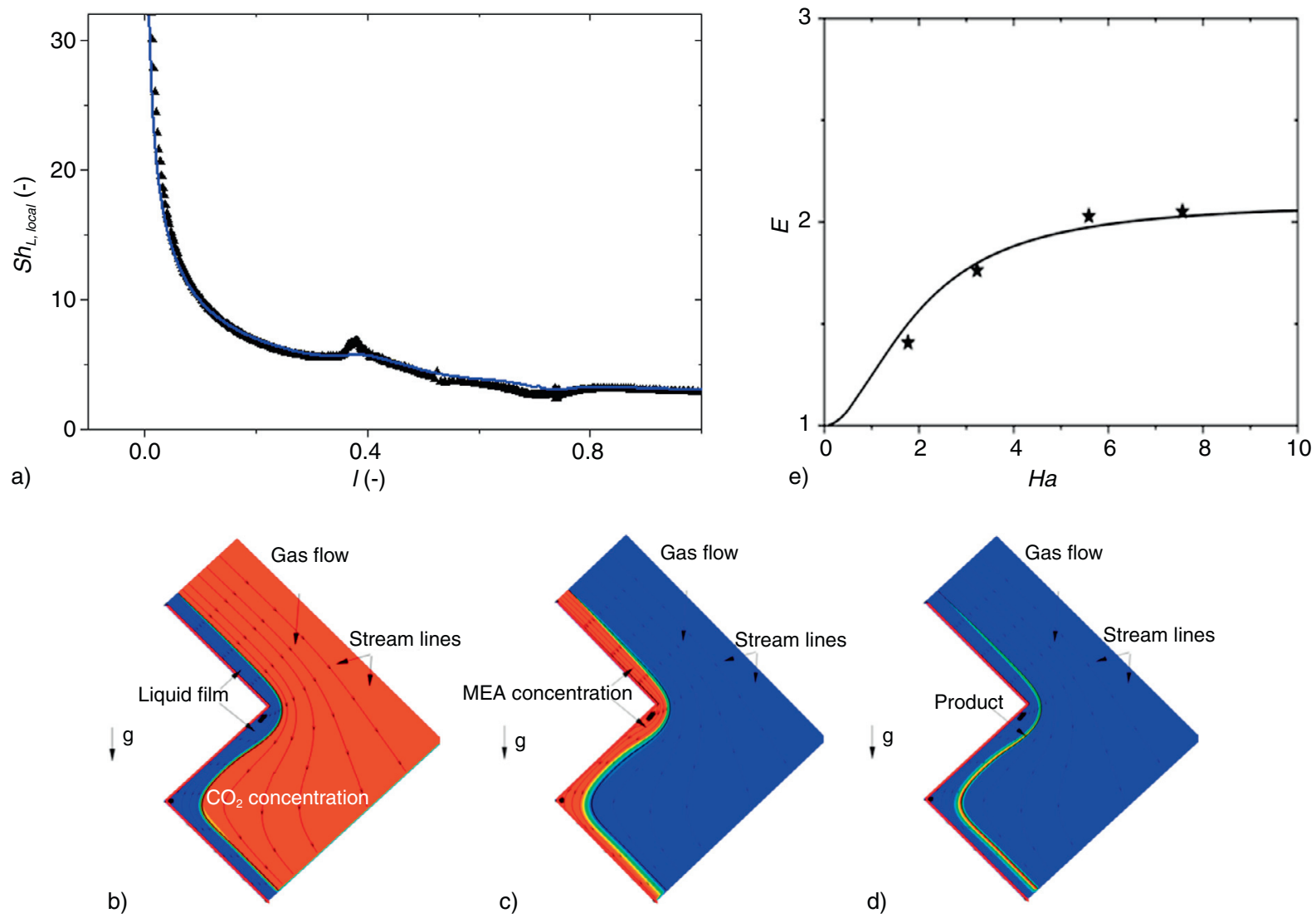

Figure 4

a) Local evolution of the liquid-side Sherwood number with the dimensionless distance from the inlet. Comparison between numerical results (triangle) and the Higbie solution (line). b) $\mathrm{CO}_{2}$, c) MEA and d) product reaction concentration contours in gas/liquid flow on structured packing. e) Enhancement factor $E$ evolution with Hatta number (Ha) for different values of second-order rate constants. Physical properties and operating conditions: $\rho_{L} / \rho_{G}=780, \mu_{L} / \mu_{G}=50, F r=5, W e=8, P e_{L}=104, Q=45 \mathrm{~m}^{3} / \mathrm{m}^{2} / \mathrm{h}$. 
transfer coefficient is well reproduced by the Higbie model when the adequate velocity and length scales are considered for exposure time determination. Figure 4a shows a comparison between the non-dimensional local liquid-side mass transfer coefficient, that is a Sherwood number, with the Higbie (1935) theory (line). It is found that the exposure time of the fluid element at the interface corresponds to the ratio between the curvilinear distance between two periodic corrugation contact points and the interface velocity, as further discussed in Haroun et al. (2012). For reactive mass transfer, the example of the transfer of $\mathrm{CO}_{2}$ in MEA (MonoEthanolAmine, a reference solvent for post-combustion carbon capture) solvent accompanied by second-order reaction in the liquid phase is presented in Figures 4b-e. The 2D plots (Fig. 4b-d) show concentration contours of $\mathrm{CO}_{2}$, MEA and the reaction product in the gas-liquid flow down a twodimensional slice of the structured packing at steady state. The results show that at steady state, the depth of penetration of $\mathrm{CO}_{2}$ in the liquid phase is very thin, indicating that the reaction occurs at the gas-liquid interface. The simulation results also show that the MEA concentration is depleted in the neighbourhood of the interface and two regions appear, the region with no reactant $\mathrm{CO}_{2}$ in the bottom of the liquid film and the region with a low concentration of MEA close to the interface. The concentration of the reaction product is mainly restricted at the gas-liquid interface. Finally, the CFD acceleration factor (Haroun et al., 2012) is compared with the approximate solution presented by Brian et al. (1961). Figure 4e shows the evolution of the enhancement factors $E$ between the gas and liquid phases with the Hatta number. Very good agreement with the solution of Brian et al. (1961) is obtained, indicating that the VOF approach is well adapted to deal with problems of reactive absorption in complex geometries.

As discussed in Raynal et al. (2013), such CFD modeling can be very useful to understand the impact of the packing geometry, physical parameters of fluids and the shape of flow on physical and reactive mass transfer and the development of physical models as well.

\subsection{Gas-Side Mass Transfer}

In Section 1.1, it is shown that, by using the REU of structured packing and the $k-\omega$ SST low Reynolds model with periodic boundary conditions, the gas flow behaviour and the dry pressure drop can be predicted with good precision. Similarly, it is shown in the present section that the REU element can also be used to estimate the impact of the flow behaviour on the gas-side mass transfer. This parameter is of prime importance in some reactive absorption applications such as the reactive absorption of $\mathrm{H}_{2} \mathrm{~S}$ from the acid natural gas in amine solvent; the main resistance of mass transfer is usually concentrated in the gas phase and, thus, the gasphase flow analysis provides important information.

In this approach, the liquid film flow is not considered in the calculation; the walls of structured packings are considered as the gas-liquid interface. It is assumed that the thin mass boundary layer of gas next to the wall is equivalent to the mass boundary layer next to the gas-liquid interface. This simplification is valid as long as there is little gas/liquid interaction. Indeed, it is well known that waves can form on the surface of a free-falling liquid film (Tailby and Portalski, 1962; Pierson and Whitaker, 1977; Ishimatsu et al., 1990) that can change the transfer mechanism compared with a smooth interface. However, it is also well known that the effective area for high liquid loads is found to be very close to the geometric area, while waves would lead to an efficient area significantly higher than the geometric area. Moreover, the experimental work of Wang (2012) showed that gas-side mass transfer is independent of the liquid flow rate. The assumption of a flat wall to represent the gas layer next to the liquid interface is therefore thought to be reasonable. A similar approach was used by Erasmus (2004) for the calculation of gas-side mass transfer in a simplified geometry of structured packings. More recently, with the same idea by simulating gas flow only, Lautenschleger et al. (2015) used CFD to analyse the impact of flow behaviour on gasside mass transfer in novel and conventional structured packing. For the determination of gas-side mass transfer, the authors consider a fast reaction of $\mathrm{H}_{2} \mathrm{~S}$ from $\mathrm{N}_{2}$ by $\mathrm{NaOH}$. The phase interface was represented by a packing wall. The authors reported very good agreement between the numerical simulation and literature modeling for Sulzer BX and Montz B1-500 commercial structured packings.

In this work, the analogy of Chilton-Colburn (Chilton, 1934) is used to calculate the gas-side mass transfer coefficient from heat transfer simulations from the packing wall. The energy equation is solved with the mass and momentum equation. The dimensionless numerical gas-side mass transfer coefficient, the Sherwood number, is then calculated from the CFD Nusselt number computed from the thermal gradient at the wall and Chilton-Colburn analogy as follows:

$$
\begin{gathered}
N u=\frac{1}{S} \iint_{S} \frac{k \nabla T}{k \frac{T_{w}-T_{b}}{d_{e q}}} d S \\
\frac{S h}{S c^{1 / 3}}=\frac{N u}{P r^{1 / 3}}
\end{gathered}
$$

where $k, T_{w}, T_{b}, S h, S c, N u$ and $P r$ are the effective conductivity, wall and bulk temperatures, Sherwood numbers, Schmidt numbers, Nusselt numbers, and Prandtl numbers, respectively. The CFD simulations presented in this section 


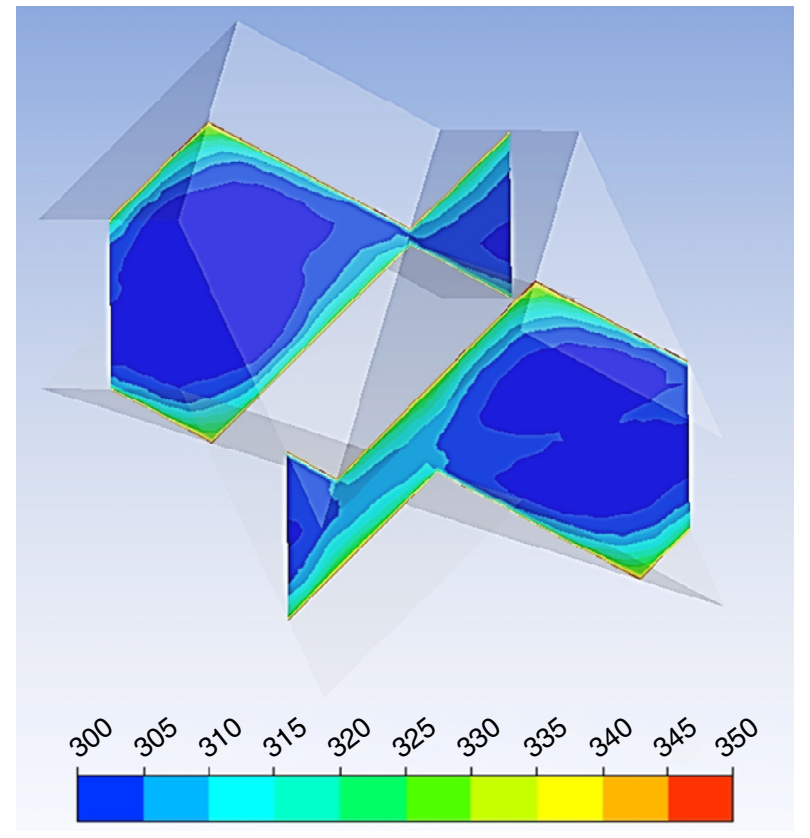

Figure 5

Temperature contour in the REU element of Mellapak 250X structured packing at Reynolds equal to 15000.

were carried out with the commercial CFD software ANSYS Fluent 14.5.

Figure 5 shows an illustration of the temperature contour plot obtained in the REU corresponding to M250X structured packing. As expected, there exists a temperature drop from the wall to the bulk, due to the lower temperature value near the bulk. The CFD results are compared with the model and experimental data of Wang (2012) and the correlation of Brunazzi (1997) for different gas Reynolds numbers and shown in Figure 6. Very good agreement between REU CFD simulations and the experimental data and physical model of Wang (2012) is observed. The relative deviation between CFD and experimental data is about $10 \%$. However, a higher deviation is obtained with the correlation proposed by Brunazzi (1997) at large Reynolds numbers with relative deviation of about $25 \%$.

Nevertheless, the presented gas-side mass transfer calculation approach appears to be applicable for the investigation of the gas-side mass transfer in structured packing and the comparison of different packing geometries.

\subsection{Effective Area and Liquid Hold-Up}

The effective area, $a_{e}$, in structured packing is defined as the effective interfacial area developed by the liquid phase normalised by the packing volume. This parameter is of

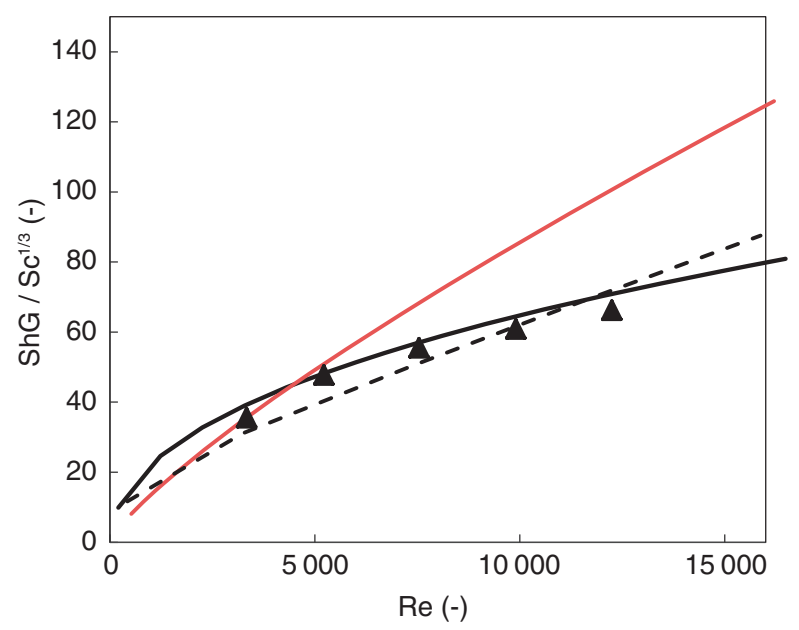

Figure 6

Comparison between gas-side mass transfer in Mellapak 250X packing resulting from REU CFD simulations (dotted line) and the experimental measurements of Wang 2012 (symbol), the model of Wang 2012 (black line) and the model of Brunazzi 1997 (red line) for a liquid load of approx. $40 \mathrm{~m}^{3} / \mathrm{m}^{2} / \mathrm{h}$.

determinant importance for reactive absorption applications. Indeed, in post-combustion $\mathrm{CO}_{2}$ capture processes, for example, Raynal et al. (2013) show that the most important mass transfer parameter is the interfacial area, the gas and liquid mass transfer coefficients having almost no influence.

In recent years, the VOF CFD approach has been used more and more to investigate wetting, the effective area and liquid hold-up in structured packing (Ataki and Bart, 2006; Hoffmann et al., 2006; Shojaee et al., 2011; Haroun et al., 2014; Sebastia-Saez et al., 2013; Iso et al., 2013; Iso and Chen, 2011). Indeed, this method is adapted to simulate wetting phenomena since it is possible to specify a wall adhesion angle in conjunction with the surface tension model (Raynal et al., 2009). A given contact angle $\gamma$ can be imposed at the wall to specify the adherence characteristic of the packing surface. This latter is then used to adjust the surface normal in cells near the wall. The combination of this contact angle with the calculated surface normal one cell away from the wall determines the local curvature of the surface, and this curvature is used to adjust the body force term in the surface tension calculation.

Recently, Haroun et al. (2014) applied a VOF method to investigate the effective area and liquid hold-up within the REU of Mellapak 250X structured packing. The values of liquid-solid contact angles were varied to mimic the geometrical imperfections of the plate surface. The results showed significant variations of the wetted area depending on the liquid-solid contact characteristics and liquid flow rate. 


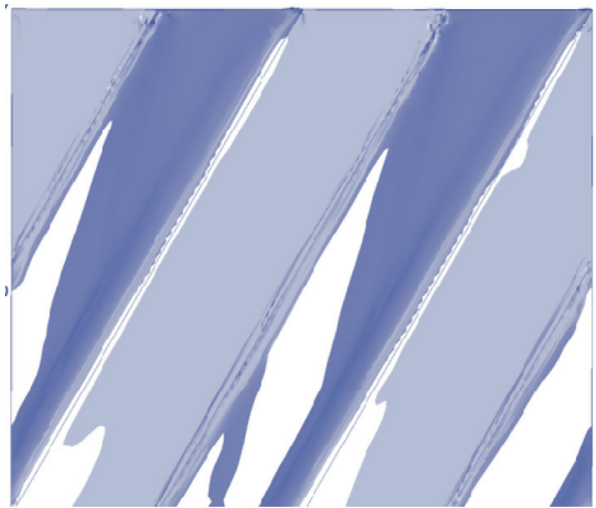

a)

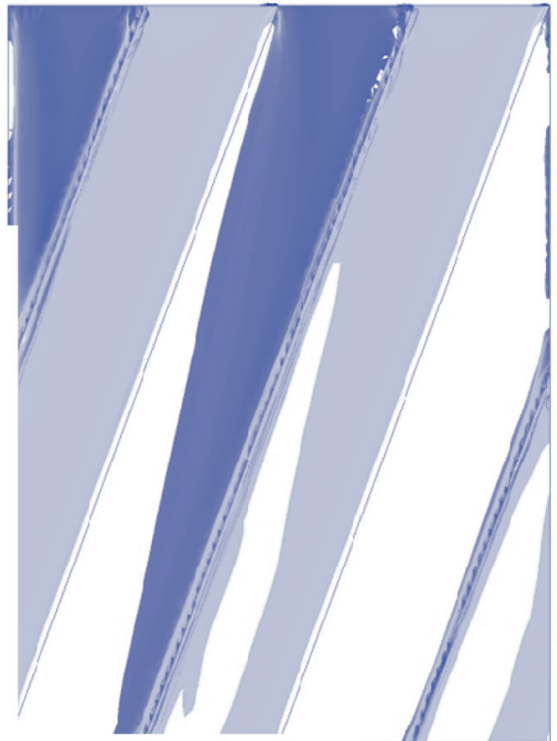

b)

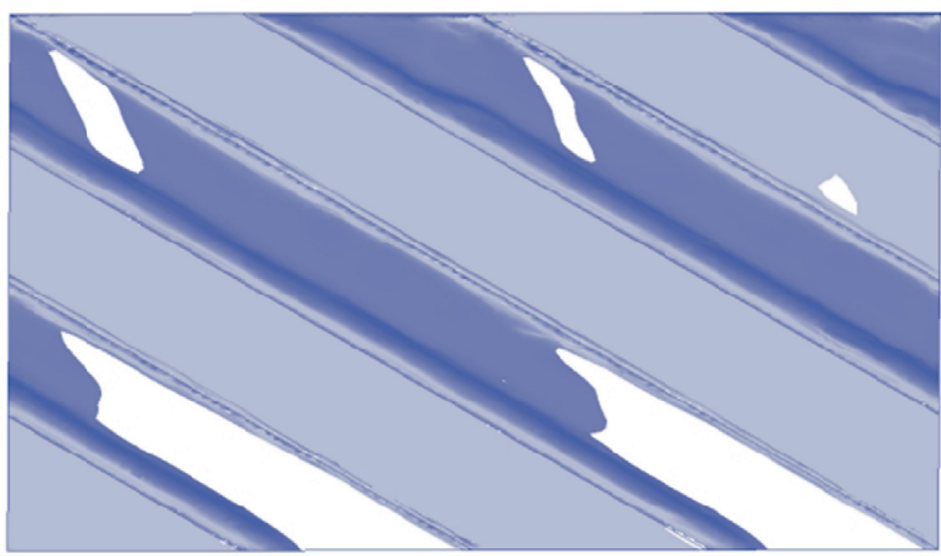

c)

Figure 7

Typical liquid film flow on the surface of the REU of structured packing for $R e_{L}=100, R e_{G}=3300$ and $\gamma=10^{\circ}$ with different channel orientations from horizontal $\theta$, a) $\theta=60^{\circ}$; b) $\theta=70^{\circ}$; c) $\theta=30^{\circ}$. The coloured surface corresponds to the iso-contour surface $\alpha=0.5$.

The comparison between the CFD effective area and the experimental data of Tsai et al. (2011) shows that the best agreement with experimental data is obtained with a static angle of $\gamma=10^{\circ}$, the deviation being about $20 \%$.

For the liquid hold-up prediction, the authors obtain good agreement between CFD and literature modeling.

Despite the interesting results with a static angle $\gamma=10^{\circ}$, the authors pointed out the lack of experimental studies on the wetting in structured packing to check the reliability of the numerical results. Nevertheless, the method appears to be appropriate for a reasonable estimation of interfacial area and liquid hold-up and for the comparison between different packing geometries. In this work, an illustration of such CFD calculations carried out with the commercial CFD software ANSYS Fluent 14 is presented.

The CFD VOF approach is applied to calculate the effective interfacial area in REU structured packings with different channel angle orientation from horizontal $\theta$ for a fixed packing geometric area $a_{G}=250 \mathrm{~m}^{2} / \mathrm{m}^{3}$. Computational options as well as boundary conditions and fluid system property details can be found in Haroun et al. (2014).

Characteristic shapes of the liquid film flow on the surface of corrugated sheet are shown in Figure 7 for different channel angle orientation. The simulation results show that an 
increase in channel angle orientation from the horizontal leads to a decrease in the packing wetted area and thus in the interfacial effective area. Indeed, for $\theta=70^{\circ}$ the liquid flows more in the hollow of the packing corrugation, further resulting in a decrease in the wetted area. On the contrary, for low channel angle orientation from the horizontal, the liquid flows over all the packing surface, thus increasing the wetted area. This behaviour is quantified in Figure 8, where the CFD effective interfacial area evolution with the liquid flow rate is presented for the different channel orientation angles considered. The results show clearly that a decrease in channel angle orientation from the horizontal leads to an increase in effective area values for different Reynolds numbers.

Such a parametric CFD effective interfacial area calculation combined with pressure drop and mass transfer analysis appears to be a powerful tool for first structured packing characterisation, as well as for the optimisation of new packing geometry. These parameters could be further used in process simulation on a larger scale for the development and design of efficient reactive absorption columns.

\section{ABSORBER INTERNAL DEVELOPMENT USING CFD}

All previous results implicitly assume that local velocities correspond to the process operating conditions, which implies perfectly homogeneous flow distribution. To make sure that perfect distribution is reached in packed towers, one has first to develop efficient internals, that are gas and

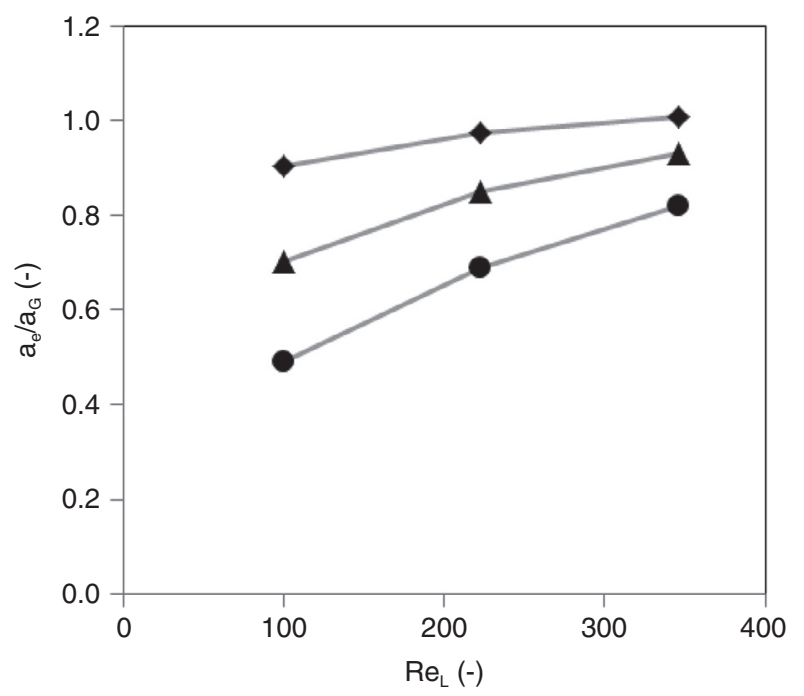

Figure 8

Dimensionless interfacial effective area versus liquid Reynolds number for different channel orientations: $\theta$. (•) $\theta=70^{\circ} ;(\boldsymbol{\Delta}) \theta=60^{\circ} ;(\diamond) \theta=30^{\circ}$. liquid distributing devices, and second to make sure that this good distribution is maintained along the bed, which is known to be impossible and requires splitting a packed column into multiple packed beds with collecting and distributing devices in between.

Concerning phase distribution evolution in packed columns, one is interested in determining the maximum bed length that can be designed before considering redistributing phases. This knowledge is mostly given by experience from the field since it is quite difficult to perform experimental tests on very large-diameter columns. A maximum bed height is thus given either in terms of maximum absolute height or in terms of maximum number of theoretical stages per bed (respectively, from $8 \mathrm{~m}$ to $12 \mathrm{~m}$ or from 10 to 20 stages depending on the packing considered and the vendor); it is sometimes given in terms of the height to diameter ratio. This upscaling issue has recently been addressed with original CFD developments via the integration of liquid phase dispersion modeling (Fourati et al., 2013); however, the simulation tool has not yet been used either for identifying the relationship between operating conditions, bed height and maldistribution phenomena or for design purposes; this would require further work and is thus not further discussed in the present paper. On the contrary, CFD can be used as a design tool for distributing devices, as is discussed in the next paragraph.

The uniform distribution of gas and liquid above packings is indeed very important to achieve optimum performance of a reactive absorption column. Poor distribution reduces the effective wetted packing and promotes liquid channelling and poor gas/liquid contact efficiency, resulting in a higher HETP (Height Equivalent to a Theoretical Plate). Consequently, the gas-liquid distributors play a major role to ensure utilising the full potential of the packed bed.

Most of the work done (Moore and Rukovena, 1987; Olujic and de Graauw, 1989, 1990; Olujic et al., 2004) shows that the sources and the nature of large-scale liquid and gas maldistribution are often due to insufficient quality of the initial distribution. In this context, CFD has become a very frequently used tool to improve the design of gasliquid distributors and to ensure the scale-up to industrial size. With this purpose, Stemich and Spiegel (2011) and Raynal et al. (2013) showed how CFD can be used to evaluate the vapour velocity distribution at the entrance to the packed bed above the vapour feed, and define design rules. Mohamed Ali et al. (2003) used CFD as an effective tool for analysing and comparing the distribution performance of internals encountered in packed columns, such as initial gas distributors, liquid distributors and liquid collectors. The comparison of measured and predicted profiles for single-phase gas flow conditions indicates good agreement. By using the CFD VOF approach, Heggemann et al. (2007) investigated liquid outflow through the distributor 


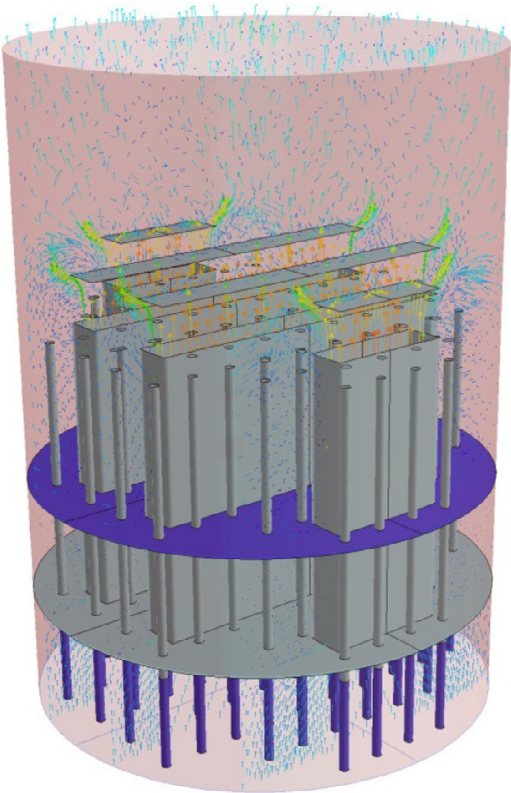

a)

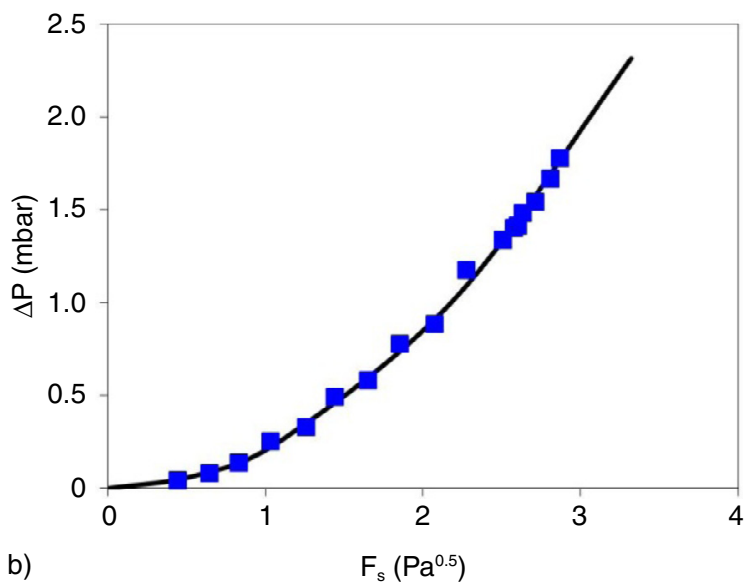

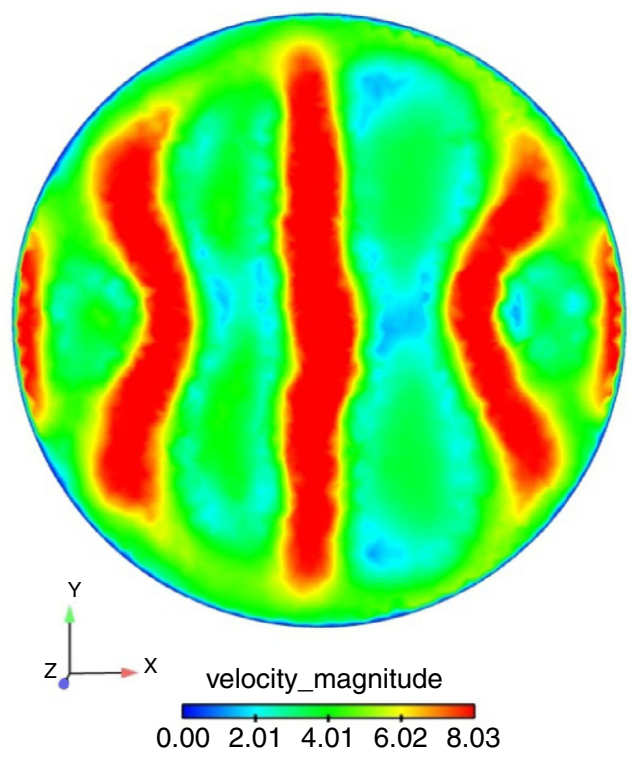

c)

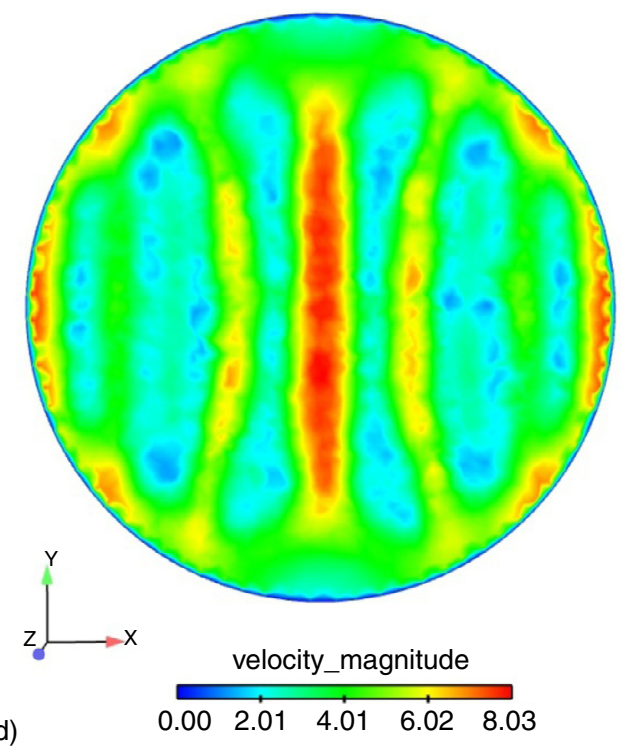

\section{Figure 9}

Picture of a 1-m-diameter tray with gas velocity vectors obtained from a gas-only simulation; b) pressure drop curve across the distributor, comparison between CFD calculations (line) and experiments (squares); c) velocity contours in a plane above the tray with 4 chimneys for gas flow; d) velocity contours in a plane above the tray with 6 chimneys for gas flow.

orifices and the influence of the lateral fluid velocity on the orifice coefficient in the liquid channel distributor tray.

In the following, typical CFD calculations performed to improve liquid and gas tray distributors are presented. Moreover, the use of CFD to build or improve the design rules is discussed. CFD simulations presented in this section were carried out with the commercial CFD software Fluent 5.4 and ANSYS Fluent 14.

\subsection{Liquid Distributors}

As discussed above, the liquid distribution tray plays an important part in the efficient operation of a reactive absorption column. Different types of commercial distributor trays can be found: perforated pipe, orifice distributors, and tunnel or channel distributors (Kister, 1990). Figure 9a shows an illustration of a common deck-type liquid distributor. 


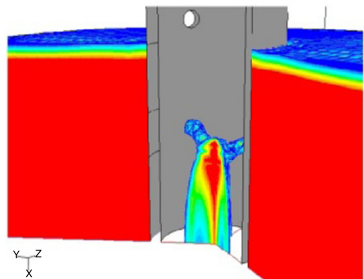

a)

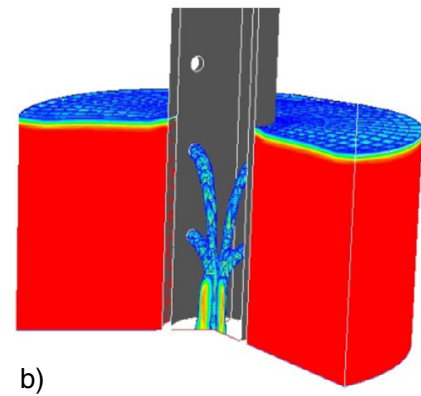

b)

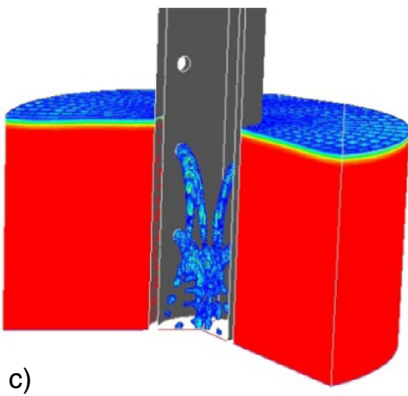

c)

Figure 10

VOF simulations of the liquid flow through a drip tube with the liquid flow rate and surface tension's respective influence, only $2 / 3$ of the geometry being shown; a) air $/$ water system for $Q_{L}=6 \mathrm{~m}^{3} / \mathrm{m}^{2} / \mathrm{h}$, b) $Q_{L}=14 \mathrm{~m}^{3} / \mathrm{m}^{2} / \mathrm{h}$, c) similar to b) but with $\sigma=20 \mathrm{mN} / \mathrm{m}$.

The latter consists of a deck equipped with covered rectangular chimneys for gas flow and drip tubes for liquid flow. This figure (Fig. 9a), where gas velocity vectors are shown, corresponds to a gas-only $k-\omega$ simulation, the aim of which is first to determine the pressure drop across the distributor, and second to optimise the number and shape of gas chimneys. It is seen from Figure $9 b$ that the comparison between CFD calculations and experimental measurements is excellent, the measurements being performed on a 1-m-diameter column with air at atmospheric pressure. This good agreement implies a good velocity distribution description and further allows design optimisation. Figures 9c, d show velocity contours in a plane $0.1 \mathrm{~m}$ above the gas chimney covers for two different designs, one with 4 gas chimneys, the other one with 6 . High velocity zones can clearly be identified with velocities as high as $8 \mathrm{~m} / \mathrm{s}$ and even higher, the superficial gas velocity being $3 \mathrm{~m} / \mathrm{s}$ only. It is clearly seen that, when increasing the number of gas chimneys from 4 to 6 , the zones of high velocity strongly decrease, which may avoid any liquid re-entrainment to the upper packed bed, leading to efficiency loss.

Depending on plugging risks, liquid operating ranges and operating conditions, one would consider drip tubes with side circular or slotted orifices, or with overflow weirs; perforations in the tray can also be used instead (Kister, 1990). In some high-performance designs corresponding to operation with a high turndown ratio, the distributors can be enhanced by using perforated drip tubes with orifices at different levels on the tubes. Such a solution must be carefully engineered to ensure a good distribution quality (Bazer-Bachi et al., 2013). For this case, the design rules have to take into account several parameters, such as the liquid height at nominal and turndown flow conditions, the distance between the gas-liquid interface and the drip tube orifice(s), the number and the area of orifices, the friction coefficient at the orifice, the resistance to the tray unlevelness, etc. Once again, CFD can be of great help to design the shape and number of orifices. Figures 10a, b show liquid contours, obtained with the VOF approach described in Raynal and Harter (2001), for two liquid flow conditions corresponding to air/water physical properties and liquid flow rates of 6 and $14 \mathrm{~m}^{3} / \mathrm{m}^{2} / \mathrm{h}$, respectively. The main difference between the two cases is of course the liquid height on the tray and the fact that in the higher flow rate case two levels of orifices dispatch liquid, while there is only one level for the lower flow rate case. One also observes that, in both cases, the liquid jets from the orifices meet along the axis into one liquid jet further going down to the packed bed downstream, which is the flow configuration which would be expected for proper operation in counter-current mode for avoiding too much liquid entrainment. Figure 10c shows a case similar to case $b$, that is, with the same liquid flow rate but for different physical properties, the surface tension being changed from $73 \mathrm{mN} / \mathrm{m}$, corresponding to water, to $20 \mathrm{mN} / \mathrm{m}$, corresponding to a light naphtha, which covers the case of amine-based solutions characterised by surface tension in the range of $40-50 \mathrm{mN} / \mathrm{m}$ (Asprion, 2005). One observes in the latter case that the liquid jets break up into droplets, which means, in the case of a counter-current flow, a risk of liquid entrainment if the gas velocity inside the tube is too high, which calls for good design of gas chimneys, as previously discussed.

For offshore applications, where the reactive absorption unit is on a floating vessel such as a Floating Liquefied Natural Gas vessel (FLNG) or a Floating Production Storage and Offloading vessel (FPSO), the column undergoes wave motions and is subject to significant accelerations which might affect transfer efficiency and fluid distribution. From a design point of view, this could lead to an increase in absorption unit size (higher packed bed heights, cumbersome distribution internal) to avoid any risk of off-spec gas being sent to the liquefied gas production unit. Therefore, 
a)

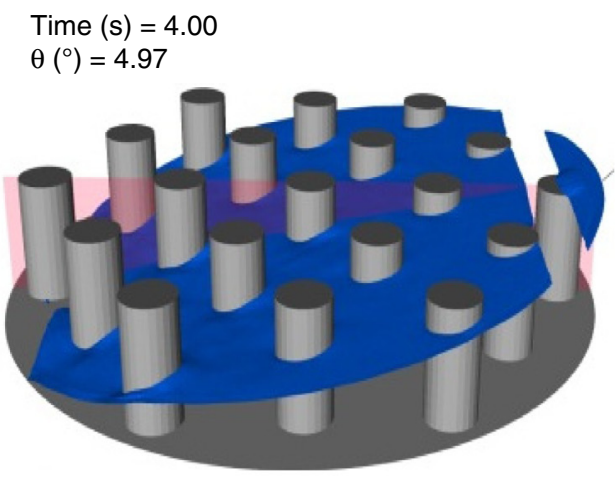

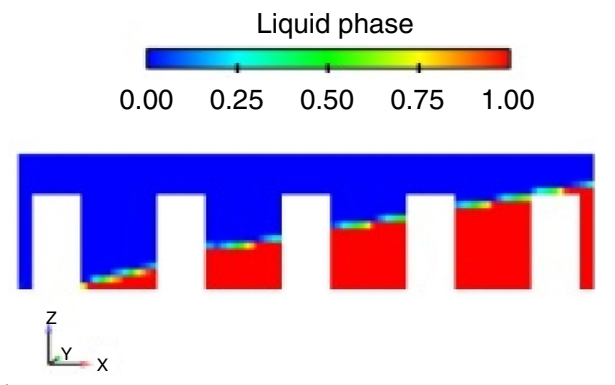

b)
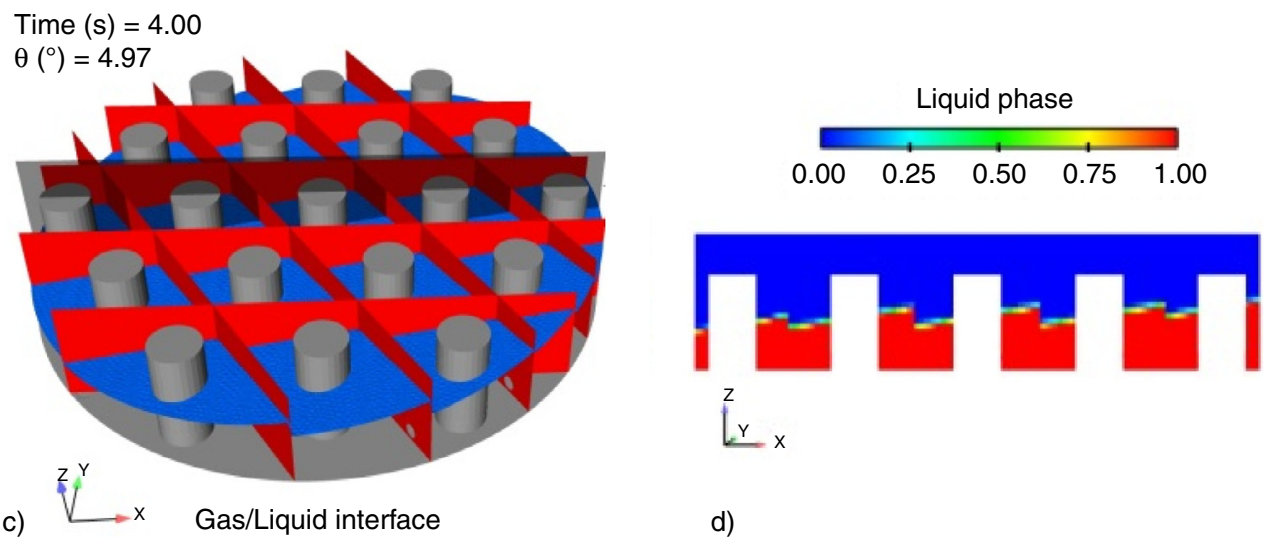

d)

Figure 11

Illustration of the liquid guard level at the maximum oscillating angle with the standard orifice pan distributor $(\mathrm{a}, \mathrm{b})$ and partitioned distributor tray (c, d).

development of efficient and compact distribution technologies that are less sensitive to motion is crucial to reduce floating absorption unit investment cost.

For offshore applications, the use of the CFD VOF approach is particularly interesting for the evaluation and design of high-performance distributors, since experiments in dynamic floating conditions are less accessible and are much more expensive than a classical static experimental setup. Moreover, this method has been validated upon experimental data on sloshing liquid in moving tanks. (Wacławczyk and Koronowicz, 2008; Li et al., 2014) Recently, in the patent US 20130277868 (Haroun et al., 2013), the inventors used CFD to develop a new distributor tray for a packed column on a floating installation (FPSO, FLNG) submitted to wave oscillating motion.

The inventors used the VOF method in floating conditions to evaluate the performance of a standard orifice pan distributor tray and new partitioned distributor tray. The motion effect on reactive absorption columns has been taken into account in the calculation through body force terms (Celebi and Akyildiz, 2002) derived from a moving coordinate system and introduced, in the framework of the moving distributor, as source terms via an in- house userdefined function using Fluent CFD software. These forces introduce into the calculation the effect of rolling motion and acceleration of fluids. The rolling conditions considered correspond to distributors positioned at the top of the column, about $50 \mathrm{~m}$ above the gyration centre of the boat. The roll oscillation amplitude and period used are $\pm 5^{\circ}$ and $15 \mathrm{~s}$, respectively.

Figure 11 shows at the maximum oscillating angle the liquid guard shape obtained by CFD VOF simulations for the conventional orifice pan distributor (Fig. 11a, b) and partitioned distributor tray (Fig. 11c, d). Figure 11a, c shows the three-dimensional shape of the gas-liquid interface and Figure $11 \mathrm{~b}, \mathrm{~d}$ gives the contour of the liquid phase on a two-dimensional slice of the distributors. The results show that with the conventional onshore distributors (Fig. 11a, b) the liquid interface is greatly disturbed in floating motion conditions, resulting in a poor liquid distribution. In contrast, 


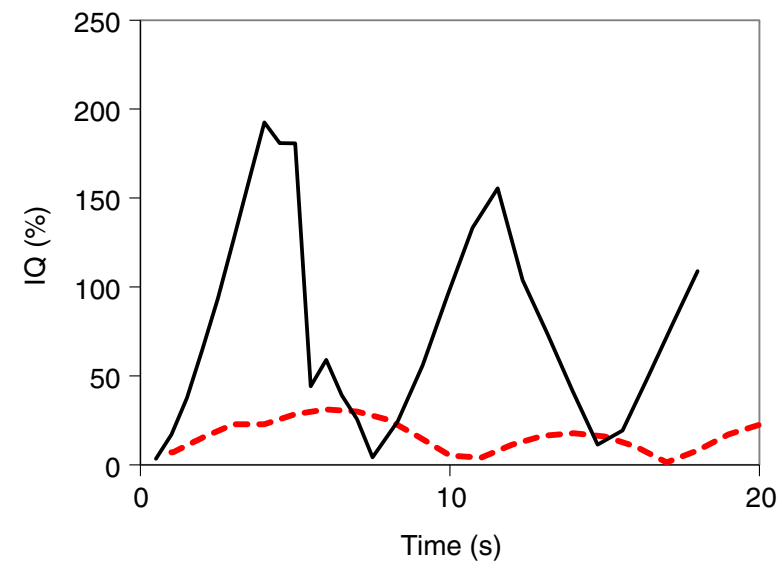

Figure 12

Evolution of the distribution Quality Index (IQ) (see Eq. 8) with floating motion time; (line) onventional orifice pan distributor; (dotted line) partitioned distributor tray. in the partitioned distributor tray (Fig. 11c, d), the baffles allow the reduction of liquid inertia induced by wave motion and thus ensure a homogeneous liquid level on the distributor. This results in appropriate liquid distribution on the packed bed. This is well illustrated in Figure 12, which shows the evolution of the distribution Quality Index, IQ, with floating motion time for conventional and novel distributor trays. A low value of the IQ indicates a good distribution quality and low sensitivity of the distributor to the oscillating motion. By contrast, a high value of the IQ points to a strong imbalance of distribution.

From the plot, a high imbalance of distribution is obtained with the conventional distributor with a maximum IQ as high as $150 \%$ and even higher. It is clearly seen that with the partitioned distributor tray, the distribution IQ strongly decreases, which indicates a good distribution performance.

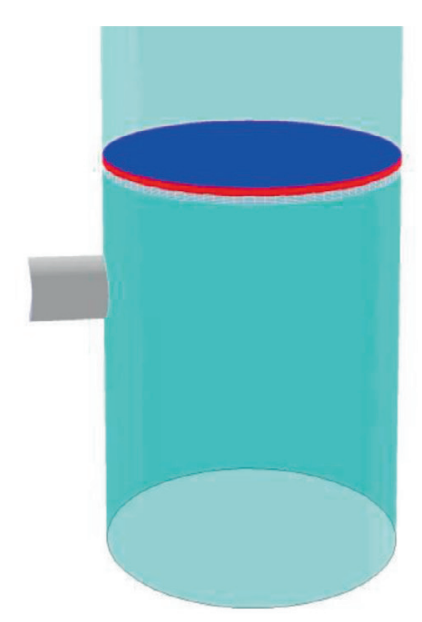

a)

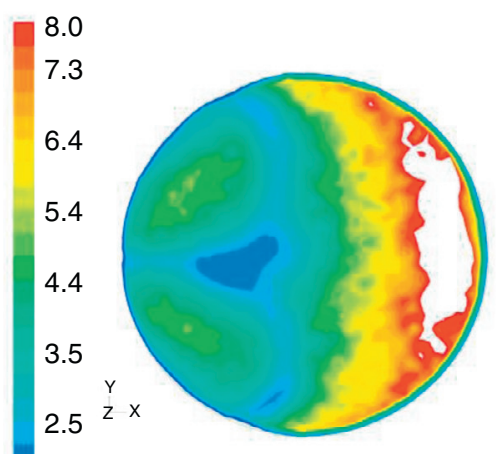

1.5 d)

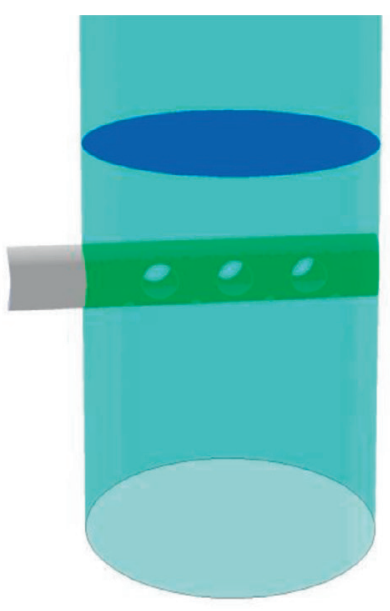

b)

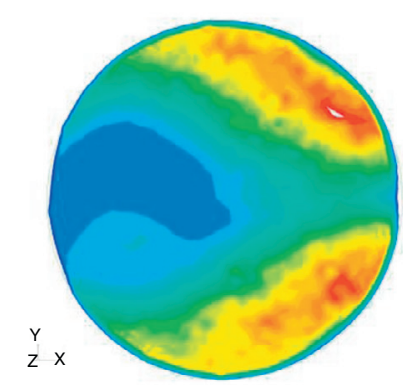

e)

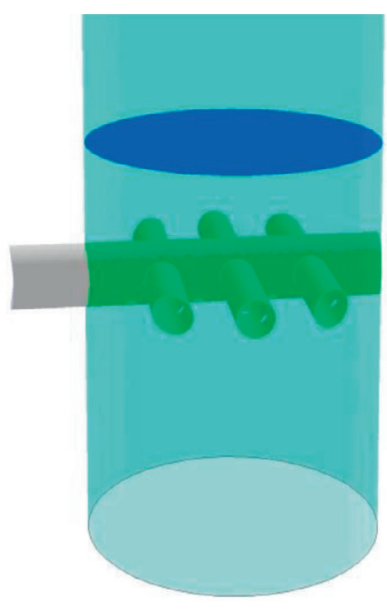

c)

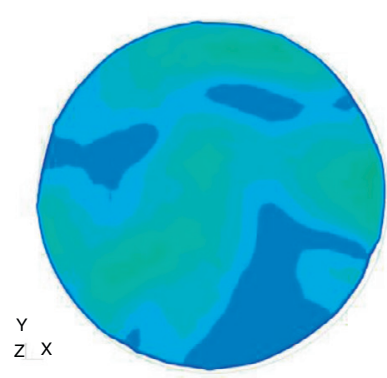

f)

Figure 13

Gas distributor configurations and corresponding velocity contours at the packed bed inlet; a, d) no gas distributor; b, e) simple perforated tube; c, f) perforated pipe distributor. 
Further developments such as parametric CFD simulations will optimise this design and improve the distribution quality index:

$$
\mathrm{IQ}=\frac{F_{\max }-F_{\min }}{F_{\text {average }}}
$$

where $F_{\max }$ and $F_{\min }$ are, respectively, the maximum and minimum liquid flows through the pan orifice distributors, and $F_{\text {average }}$ represents the average liquid flow.

\subsection{Gas Distributors}

Gas or vapour distributors are used to achieve a uniform gas flow at the packed bed inlet. Depending on the service, pressure drop can be a specification and must be minimised; in natural gas treatment, this would not be an issue, while for $\mathrm{CO}_{2}$ post-combustion capture this would be critical. Gas flow simulations are quite easy to perform and can be used for gas distributing device testing and design (Mohamed Ali et al., 2003; Stemich and Spiegel, 2011; Raynal et al., 2013). Indeed, as can be seen from Figure 13, it is possible to evaluate the quality distribution at the packed bed inlet, downstream of the distributor, for different distributors. We considered cases without any distributor (Fig. 13a), with a simple large perforated tube (Fig. 13b) or with a multiple perforated pipe distributor (Fig. 13c). Calculations were performed in the framework of $\mathrm{CO}_{2}$ capture in an 8-m-diameter column with a standard $k-\varepsilon$ turbulent model. The use of a simple tube, which was believed to provide some improvement, does not make any change with the case without any internal, the maximum velocity still being above $8 \mathrm{~m} / \mathrm{s}$ for a superficial gas velocity of $2 \mathrm{~m} / \mathrm{s}$. The ladder-type distributor provides a significant improvement for moderate complexity; the quality index, as defined in the previous section, was improved by a factor of 10 , decreasing from $269 \%$ to $20 \%$. However, this improvement has a cost since the associated pressure drop increases from 104 mbar up to 200 mbar.

\section{CONCLUSION}

The aim of this paper was to illustrate on a large spectrum how CFD is used for packed absorption tower optimum design. It is shown how the simulation tool can complete experiments either by providing supplementary information that experiments can provide too, at least partially, such as mass transfer coefficient determination, or by providing supplementary information that experiments cannot address, or with limiting inputs, in particular linked to scale-up issues, such as internal design.
It is first important to underline that both tools really complete each other: on the one hand, CFD calculations can provide sensitivity analysis or extrapolation to operating conditions and corresponding physical properties outside the accessible range of experiments; on the other hand, CFD calculations will still require validation since the development of new closure models, for example concerning wetting of phase dispersion phenomena, are still not fully understood and integrated into physical models one can easily use. Second, CFD can address gas only or gas/liquid flows over a very large range of characteristic lengths via the use of different approaches in quite a time-efficient way so that it can be used for the development or optimisation of new design rules, from asperities on the packing wall to a full industrial-size $3 \mathrm{D}$ column solving the flow within the packed bed and through column internals.

For future developments, further CFD investigations and validation should first focus on the wetting phenomena and on improving the modeling of the contact angle in the roughness surface. This could lead to improving the prediction of the effective area in structured packing and also to extending the prediction of pressure drop to gas-liquid flow conditions.

Second, regarding the upscaling issue, the future development of the two-fluid models with porous medium description (Fourati et al., 2013) will allow identifying the relationship between operating conditions, bed height and maldistribution phenomena on an industrial column scale. Moreover, hydrodynamic simulations using a two-fluid model could be coupled with chemical species transport and reactive absorption modeling. Such an approach would allow quantifying the impact of hydrodynamic distribution on the packing transfer performance and thus better definition of design criteria for distribution technologies.

It is thus believed that CFD should be a more and more useful tool for R\&D chemical engineers who develop new solutions to optimise absorption column design.

\section{ACKNOWLEDGMENTS}

The authors would like to acknowledge Dr. M. Fourati and M. Morin for their collaboration in CFD modeling of gas-side mass transfer and P. Ancelet for her collaboration in CFD modeling of effective area in structured packing.

\section{REFERENCES}

Ataki A., Bart H.J. (2006) Experimental and CFD simulation study for the weeting of s structured packing element with liquids, Chem. Eng. Technol. 29, 3, 336-347.

Asprion N. (2005) Surface tension models for aqueous amine blends, Ind. Eng. Chem. Res. 44, 7270-7278. 
Bai H., Theuerkauf J., Gillis P.A. (2009) A Coupled DEM and CFD Simulation of Flow Field and Pressure Drop in Fixed Bed Reactor with Randomly Packed Catalyst Particles, Ind. Eng. Chem. Res. 48, 4060-4074.

Bazer-Bachi F., Haroun Y., Augier F., Boyer C. (2013) Experimental evaluation of distributor technologies for trickle-bed reactors, Ind. Eng. Chem. Res. 52, 11189-11197.

Billet R. (1995) Packed Towers, VCH Eds, Weinheim.

Bravo J.L., Rocha J.A., Fair J.R. (1985) Mass transfer in gauze packings, Hydrocarbon Processing 64, 1, 91-95.

Brackbill J.U., Khote D.B., Zemach C. (1992) A continuum method for modelling surface tension, J. Comput. Phys. 100, 335-354.

Brian P.L.T., Hurey J.F., Hassettine E.H. (1961) AIChE J. 7, 226. Brunazzi E., Nardini G., Paglianti A., Petraca L. (1995) Interfacial area of Mellapak packing Absorption of 1,1,1-trichloroethane by Genosorb 300, Chem. Eng. Technol. 18, 248.

Brunazzi E.P. (1997) Liquid-Film Mass-Transfer Coefficient in a Column Equipped with Structured Packings, Ind. Eng. Chem. Res. 36, 3792-3799.

Celebi M.S., Akyildiz H. (2002) Nonlinear modeling of liquid sloshing in a moving rectangular tank, Ocean Eng. 29, 1527-1553. Charpentier J.C. (2009) Perspective on multiscale methodology for product design and engineering, Comp. Chem. Eng. 33, 936-946.

Chilton T.C. (1934) Mass Transfer Coefficient, Prediction from Data on Heat Transfer and Fluid Friction, Ind. Eng. Chem. 1183-1187.

Danckwerts P.V. (1970) Gaz-Liquid Reaction, McGraw-Hill, New York.

Erasmus A.B. (2004) Mass Transfer in Structured Packing, Ph.D. Dissertation Chem. Eng., University of Stellenbosch, South Africa.

Fair J.R., Bravo J.L. (1990) Distillation columns containing structured packings, Chem. Eng. Prog. 86, 19-29.

Fernandes J., Lisboa P.F., Simoes P.C., Mota J.P.B., Saatdjian E. (2009) Application of CFD in the study of supercritical fluid extraction with structured packing: wet pressure drop calculations, J. Supercrit. Fluids 50, 61.

Fourati M., Roig V., Raynal L. (2012) Experimental study of liquid spreading in structured packings, Chem. Eng. Sci. 80, 1-15.

Fourati M., Roig V., Raynal L. (2013) Liquid dispersion in packed columns: experiments and numerical modelling, Chem. Eng. Sci. 100, 266-278.

Haroun Y., Legendre D., Raynal L. (2010a) Direct numerical simulation of reactive absorption in gas-liquid flow on structured packing using interface capturing method, Chem. Eng. Sci. 65, 351-356.

Haroun Y., Legendre D., Raynal L. (2010b) Volume of fluid method for interfacial reactive mass transfer: application to stable liquid film, Chem. Eng. Sci. 65, 2896-2909.

Haroun Y., Raynal L., Legendre D. (2012) Mass transfer and liquid hold-up determination in structured packing by CFD, Chem. Eng. Sci. 75, 342-348.

Haroun Y., Raynal L., Alix P. (2013) Partitioned distributor tray for offshore gas/liquid contact column, Patent US 20130277868.

Haroun Y., Raynal L., Alix P. (2014) Prediction of effective area and liquid hold-up in structured packings by CFD, Chem. Eng. Res. Des. 92, 2247-2254.

Heggemann M., Hirschberg S., Spiegel L., Bachmann C. (2007) CFD Simulation and Experimental Validation of Fluid Flow in Liquid Distributors, Chem. Eng. Res. Des. 85, 59-64.
Higbie R. (1935) The rate of absorption of a pure gas into a still liquid during short periods of exposure, Trans. AIChE 35, 365.

Hirt C.W., Nichols B.D. (1981) Volume of Fluid method for the dynamics of free boundaries, J. Comput. Phys. 39, 201-225.

Hoffmann A., Ausner I., Repke J.-U., Wozny G. (2006) Detailed investigation of multiphase (gas-liquid and gas-liquid-liquid) flow behaviour on inclined plates, Chem. Eng. Res. Des. 84, 147-154.

Ishimatsu M., Nosoko T., Nagata T. (1990) Flow patterns and wave characteristics of falling liquid films, Heat Trans. Japanese Res. 19, 602-615.

Iso Y., Chen X. (2011) Flow transition behavior of the wetting flow between the film flow and rivulet flow on an inclined wall, J. Fluids Eng. 133, 091101-91111.

Iso Y., Huang J., Kato M., Matsuno S., Takano K. (2013) Numerical and experimental study on liquid film flows on packing elements in absorbers for post-combustion $\mathrm{CO}_{2}$ capture, Energy Procedia 37, 860-868.

Kister H.Z. (1990) Distillation Operation, McGraw-Hill, New York, USA.

Lautenschleger A., Olenberg A., Kenig E.Y. (2015) Systematic CFD-based method to investigate and optimise novel structured packings, Chem. Eng. Sci. 122, 452-464.

Lassauce A., Alix P., Raynal L., Royon-Lebeaud A., Haroun Y. (2014) Pressure Drop, Capacity and Mass Transfer Area Requirements for Post-Combustion Carbon Capture by Solvents, Oil Gas Sci. Technol. 69, 6, 1021-1034.

Li H.-L., Li J., Zong Z., Chen Z. (2014) Numerical studies on sloshing in rectangular tanks using a tree-based adaptive solver and experimental validation, Ocean Eng. 82, 20-31.

Mahr B., Mewes D. (2007) CFD Modelling and calculation of dynamic two phase flow in columns equipped with structured packing, Chem. Eng. Res. Des. 85, 1112-1122.

Moore F., Rukovena F. (1987) Liquid and gas distribution in commercial packed towers, Chem. Plants and Processing No. 8, 11.

Mohamed Ali A., Jansens P.J., Olujic Z. (2003) Experimental Characterization and Computational Fluid Dynamics Simulation of Gas Distribution Performance of Liquid (Re)Distributors and Collectors in Packed Columns, Chem. Eng. Res. Des. 81, 1, 108-115.

Nikou K., Ehsani M.R. (2008) Turbulence models application on CFD simulation of hydrodynamics, heat and mass transfer in a structured packing, Int. Commun. Heat Mass Transfer 35, 1211.

Nicoud F., Ducros F. (1999) Subgrid-Scale Stress Modelling Based on the Square of the Velocity Gradient Tensor, Flow Turb. Comb. 62, 3, 183-200.

Olujic Z., de Graauw J. (1989) Appearence of maldistribution in distillation columns equiped with hight performance packings, Chem. Biochem. Eng. Q. 3, 181-196.

Olujic Z., de Graauw J. (1990) Experimental studies on interaction between the initial liquid distribution and the performance of structured packing, Separation Sci. Tech. 25, 1723-1735.

Olujic Z., Mohamed Ali A., Jansens P.J. (2004) Effect of the initial gas maldistribution on the pressure drop of structured packings, Chem. Eng. Process. 43, 465-476.

Petre C.F., Larachi F., Illiuta I., Grandjean B.P.A. (2003) Pressure drop through structured packings: breakdown into the contributing mechanisms by CFD modelling, Chem. Eng. Sci. 58, 163-177.

Pierson F.W., Whitaker S. (1977) Some theoretical and experimental observations of the wave structure of falling liquid film, Ind. Eng. Chem. Fundam. 16, 401-408. 
Raynal L., Harter I. (2001) Studies of Gas-Liquid flow through distributing devices using VOF-CFD simulations, Chem. Eng. Sci. 56, 6385-6391.

Raynal L., Boyer C., Ballaguet J.P. (2004) Liquid holdup and pressure drop determination in structured packing with CFD simulation, Can. J. Chem. Eng. 82, 871-879.

Raynal L., Royon-Lebeaud A. (2007) A multi-scale approach for CFD calculations of gas-liquid flow within large size column equipped with structured packing, Chem. Eng. Sci. 62, 7196-7204.

Raynal L., Ben Rayana F., Royon-Lebeaud A. (2009) Use of CFD for $\mathrm{CO}_{2}$ absorbers optimum design: from local scale to large industrial scale, Energy Procedia 1, 917-924.

Raynal L., Gomez A., Caillat B., Haroun Y. (2013) $\mathrm{CO}_{2}$ capture cost reduction: Use of a multiscale simulations strategy for a multiscale issue, Oil Gas Sci. Technol. 68, 1093-1108.

Said W., Nemer M., Clodic D. (2011) Modeling of dry pressure drop for fully developed gas flow in structured packing using CFD simulations, Chem. Eng. Sci. 66, 2107-2117.

Scardovelli R., Zaleski S. (1999) Direct numerical simulation of free-surface and interfacial flow, Annu. Rev. Fluid Mech. 31, 567-603.

Sebastia-Saez D., Gu S., Ranganathan P., Papadikis K. (2013) 3D modeling of hydrodynamics and physical mass transfer characteristics of liquid film flows in structured packing elements, Int. J. Greenhouse Gas Control 19, 492-502.

Sebastia-Saez D., Gu S., Ranganathan P., Papadikis K. (2014) Micro-scale CFD study about the influence of operative parameters onphysical mass transfer within structured packing elements, Int. J. Greenhouse Gas Control 28, 180-188.

Shojaee S., Hosseini S.H., Rafati A., Ahmadi G. (2011) Prediction of the effective area in structured packings by computational fluid dynamics, Ind. Eng. Chem. Res. 50, 10833-10842.
Soulaine C., Horgue P., Franc J., Quintard M. (2014) Gas-liquid flow modeling in columns equipped with structured packing, AIChE Journal 60, 10, 3665-3674.

Stemich C., Spiegel L. (2011) Characterization and quantification of the quality of gas flow distributions, Chem. Eng. Res. Design 89, 1392-1396.

Spiegel L., Meier W. (1992) A generalized pressure drop model for structured packings, Distillation and Absorption, IChemE Symp. 128, B85-B94.

Szulczewska B., Sek J., Gorak A., Zbicinski I. (2000) CFD calculation of two-phase flow on elements of structured packing, Chisa Int. Conf., Praha, Czech Republic, Aug. 27-37, Paper \#565, 1-10.

Tailby S.R., Portalski S. (1962) Wave inception on a liquid film flowing down a hydrodynamically smooth plate, Chem. Eng. Sci. 19, 283-290.

Tsai R.E., Seibert A.F., Eldridge R.B., Rochelle G.T. (2011) A dimensionless model for predicting the mass-transfer area of structured packing, AIChE J. 57, 1173-1184.

Wacławczyk T., Koronowicz T. (2008) Comparison of CICSAM and HRIC high-Resolution schemes for interface capturing, $J$. Theo. App. Mech. 46, 2, 325-345.

Wang C. (2012) Measurement of Packing Effective Area and Mass Transfer Coefficients, Luminant Carbon Management Program and Process Science and Technology Center, Austin, Texas, pp. 1-9.

Manuscript submitted in December 2014 Manuscript accepted in June 2015 Published online in October 2015

Cite this article as: Y. Haroun and L. Raynal (2015). Use of Computational Fluid Dynamics for Absorption Packed Column Design, Oil Gas Sci. Technol 71, 43. 